\title{
DISCUSSION ABOUT HBS TRANSFORMATION IN HIGH BURN-UP FUELS
}

\author{
DANIEL BARON*, MOTOYASU KINOSHITA ${ }^{1,2}$, PHILIPPE THEVENIN and RODRIGUE LARGENTON \\ EDF R\&D Les Renardières Route de Sens, 77818 MORET sur LOING Cedex France \\ ${ }^{1}$ CRIEPI /JAEA/U-Tokyo, Project leader of NXO \\ ${ }^{2}$ Central Research of Electric Power Industry, 2-11-1 Iwadokita Komaeshi, Tokyo 201 Japan \\ *Corresponding author. E-mail : daniel.baron@edf.fr
}

Received December 10, 2008

Accepted for Publication January 20, 2009

High burn-up transformation process in low temperature nuclear fuel oxides material was observed in the early sixties in LWR $\mathrm{UO}_{2}$ fuels, but not studied in depth. Increasing progressively the fuel discharge burn-up in PWR power plants, this material transformation was again observed in 1985 and identified as an important process to be accounted for in the fuel simulations due to its expected consequence on fuel heat transfer and therefore on the fission gas release. Fission gas release was one of the major concerns in PWR fuels, mainly during transient or accidents events. The behaviour of such a material in case of rod failure was also an important aspect to analyse. Therefore several national and international programs were launched during the last 25 years to understand the mechanisms leading to the high burn-up structure formation and to evaluate the physical properties of the final material. A large observations database has been acquired, using the more sophisticated techniques available in hot cells. This large database is discussed in this paper, providing basis to build an engineering-model, which is based on phenomenological description data and information accumulated. In addition this paper has the ambition to construct the best logical model to understand restructuring.

KEYWORDS : Nuclear Fuel, LWR, High Burn-up, HBS, Mechanisms, Polygonisation, Porosity, Restructuration, Rim Effect

\section{INTRODUCTION}

When EDF started to operate PWRs in 1977, a large survey program was launched, including TIHANGE, FESSENHEIM and BUGEY fuel rod examinations. It was conducted within a French collaboration program between EDF, FRAMATOME and CEA. This collaborative program was then extended to WESTINGHOUSE participation. Standard discharge burn-up was around 34 and $35 \mathrm{GWd} / \mathrm{MtU}$. In order to investigate higher discharge burn-up, four fuel assemblies were reloaded in the FESSENHEIM 2 core and four assemblies in the ZION core. The fuel rod average burn-up was increased up to 55 $\mathrm{GWd} / \mathrm{MtU}$ after a fourth and fifth cycle. Four Fessenheim fuel rods were examined in 1984 after the fourth cycle (around $45 \mathrm{GWd} / \mathrm{MtU}$ fuel rod average) and four in 1985 after the fifth cycle. The same scheme was performed after 4 and 5 cycles on the ZION rods in America.

After five cycles an abnormal porosity was observed in the outer "rim" region of the most irradiated pellets (D.Baron [2], P.Guedeney [49]). Going back on fuel irradiated for four cycles, the same observation was made but at a much lower level. In addition, EPMA was showing in the same cross section a loss of xenon in the pellet outer radius. Average porosity was evaluated around 8 to $10 \%$. Concomitant to these observations, the overall fuel rod fission gas release was exhibiting acceleration with burnup. It was then suggested that the xenon excess was coming from this area. Later, after careful investigation it was demonstrated that this conclusion was wrong and that most of the gases were stored in the newly formed porosities. The detection loss was mainly due to the EPMA depth limitation, around $1 \mu \mathrm{m}$ for the usual beam acceleration. It was demonstrated later on by increasing the electrons beam energy, that gas could be detected in unopened bubbles under the sample surface.

In conclusion, a new phenomenon was identified in the coldest part of the fuel pellet, where thermal activation is usually considered too low to allow atoms mobility (below 900K). Because of the location of these observations at the pellet edge, it was called "the RIM effect".

Further SEM images have shown that this pore buildup is then accompanied by a grain subdivision. In 1962 Bleiberg [1] had already mentioned such a remarkable micro structural change on high burn-up LWR $\mathrm{UO}_{2}$ fuels. They found from replica electron microscopy, that at around 
$75 \mathrm{GWd} / \mathrm{MtU}$ the original grain subdivided into fine sub grains, less than $1 \mu \mathrm{m}$. However no further work was launched at that time to investigate this phenomenon.

In the framework of the PWR studies, consequences on the fuel thermo-mechanical behaviour were expected, mainly on the fuel operating temperatures and therefore on the level of fission gas release. Therefore, these 1985 observations of the High Burn-up Structure (HBS) Transformation in the fuel pellet rim, led the designers to invest time and money into national and international programs to understand the mechanisms involved. The first step was to suggest a reorientation of the High Burnup Effect Program (HBEP) objectives in 1986 (D.Baron [2] and J.O.Barner [3]). EDF in 1990 launched a program on high burn-up fuel chemistry with CEA, developing a first generation model for the engineering codes, focused on simulating the porosity evolution (D.Baron [4]). The major concern was to study the consequence of this additional porosity on the evolution of the physical and mechanical properties of the material. A part of the survey programs was focused on the understanding of the transformation threshold and later on, on its mechanism.

However, the engineering survey programs were not able to support such an investigation program, which need a pragmatic scientific approach. This was the reason for EDF R\&D to join in 1994 the High Burn-up Rim Project (HBRP, 1992-2001) and then the HBRP_NT (2002-2005) proposed by the Japanese CRIEPI (M.Kinoshita [5], M.Kinoshita [6]). A well-defined parametric study was engaged within this project on fuel discs irradiated in quasi-isothermal conditions, up to $100 \mathrm{GWj} / \mathrm{MtU}$. After irradiation in the HALDEN reactor, burn-up and temperature threshold were identified and sample properties were characterized. SEM and TEM examinations in TUI have provided very useful information in particular on the dislocation piling and the nano-bubbles stabilization and growth. It should also be mentioned that a very efficient complement was also provided within the NFIR working group. NFIR5 project is expected to bring again in the next years a new stage of understanding with the irradiation of a set of parametric fuel wafers.

SIMS methodology development in CEA hot labs on nuclear fuel applications (Desgranges [7], Lamontagne [8]) is also a valuable tool to localize and quantify the fission gases, and to evaluate the gas pressure in the micrometric bubbles of the HBS. More widely, evolutions in the investigation tools and methods are necessary to go further in the mechanisms understanding.

Since 2003, more theoretical works have been conducted to study in depth the effect of cascades produced by highenergy ions in fuel materials (indeed each material atom is displaced every two or three days). These are multi-scale approaches, starting from first principle calculations [19] in order to evaluate the atoms incorporation energies or the defect formation energies of the fission products, and involving molecular dynamics and Monte Carlo calculations.
These works are performed within the Japanese interUniversities NXO project and within the new European F-BRIDGE project.

In 2007, we had collected a large amount of data from $\mathrm{UO}_{2}, \mathrm{UO}_{2}+$ additives, MOX fuels, in a large variety of operating conditions. What conclusions can be drawn? What are the questions still pending? This paper is discussing the main interrogations and available answers, pointing the existing controversies, in order to provide the best state of the art.

\section{STATE OF THE ART}

Evidence showed (Spino [9], Rest [10], Spino [11]) that the gas precipitation and the propagation of the grain subdivision don't occur at the same burn-up. Gas starts to
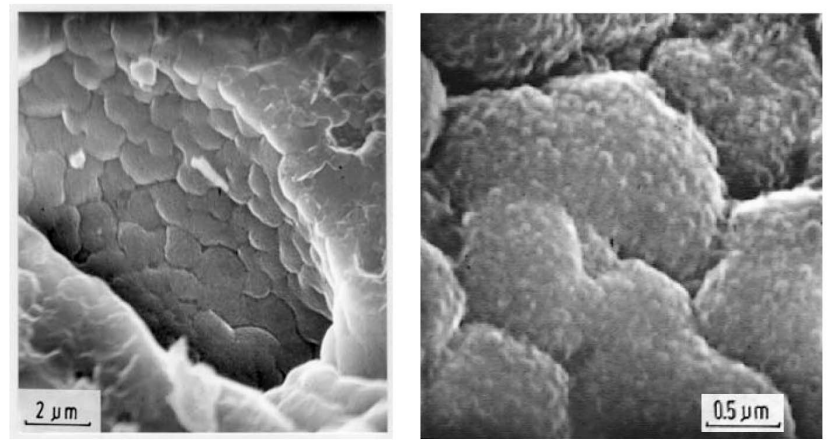

Fig. 1. SEM Image of a HBS Pore Surface (Ray [45]) The Internal Face of the HBS Pores Shows Areas of Subdivided Grains

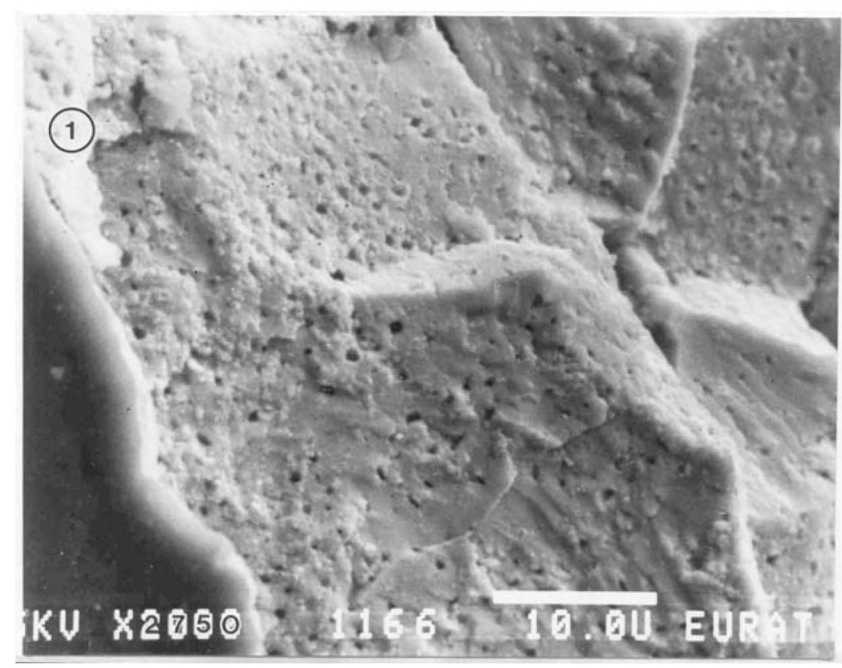

Fig. 2. N118 BR3 Fuel, 67 GWd/MtU Pellet Average Burn-up, 90 to $110 \mathrm{GWd} / \mathrm{MtU}$, Local Burn-up: very Few Grain Subdivision but Presence of Pores Decorated with Tiny Grains 
precipitate in tiny bubbles then; bubbles grow sometimes quite quickly to achieve a micrometric size. During this phase, the micrometric bubbles observed are systematically decorated with tiny grains on their surface (50 to $100 \mathrm{~nm}$ ) (figure 1). The last stage of the process is the formation of areas of sub-divided grains filling the space between micrometric bubbles. However, this step in the HBS process can be heavily delayed in some cases, as observed in the N118 BR3 fuel rod (Spino [9]) and other similar rods (figure 2). Spino [11] et al have recently shown that lattice contraction accompanies grain subdivision propagation.

Many parameters may influence the HBS transformation: the local temperature and burn-up, the instantaneous fission density, the local density of fission products, the initial grain size, the local fuel constraint, some initial additives, and the local oxygen potential. The evolution of the oxygen potential is related to the global affinity of the fission products (their valence), and to the buffers able to trap the oxygen, such as Molybdenum, or Zirconium. (J.H.Matzke $[43,44])$. It was also shown that the oxygen potential of an irradiated fuel is increasing slowly with burn-up (Spino [28]), therefore the saturation of the molybdenum oxidation is likely an element to be taken into account.

All investigation means available on irradiated fuel in hot cells have been used. The lower investigation scale available is TEM, allowing observations of one to several hundred of nanometres artefacts. However, the preparation of thin layers on irradiated samples is not possible at this time. TEM observations are then performed on selected "chips" obtained by crunching samples. This does not allow locating properly the observations performed. The following discussion is then based on the overall information collected on high burn-up fuels, combined with extrapolations suggested by deduction.

\subsection{Burn-up and Temperature Threshold (Local Values)}

Non-constrained samples were irradiated for the HBRP project, in the Halden reactor (IFA 601) in quasi-isothermal conditions at four temperatures: $450,650,900$ and $1150^{\circ} \mathrm{C}$. In order to achieve high burn-up in a short time, the fuel initial ${ }^{235} \mathrm{U}$ enrichment was $26.5 \%$. The instantaneous fission density was therefore 2 to 6 times higher than in a standard PWR fuel operating around 178 to $220 \mathrm{~W} / \mathrm{cm}$ and the instantaneous fission density was different depending upon the final discharge burn-up of the Samples, as shown in table 1.

This means that the instantaneous energy deposit was, except for the samples with the lowest burn-up (35 $\mathrm{GWd} / \mathrm{MtU}$ ), higher in these fuels than in standard PWR fuels, even in the self-shielding area of an $\mathrm{UO}_{2}$ pellet, or in the rich Plutonium agglomerates of the MOX fuels. Having all this in mind, the burn-up threshold for HBS initiation was found between 55 and $65 \mathrm{GWd} / \mathrm{MtU}$ and the temperature threshold below $1100^{\circ} \mathrm{C}$ (M.Kinoshita [13]). The accuracy on these thresholds is obviously limited. HBS initiation could be detected very locally in the $55 \mathrm{GWd} / \mathrm{MtU}$ and all samples above $65 \mathrm{GWd} / \mathrm{MtU}$ were totally restructured. The burn-up threshold is then in between these two values. It gives low information on the real kinetic of the mechanism.

Related to the particular power density and constraint of the HBRP samples, 55-65 GWd/MtU is probably a conservative value with regard to HBS transformation kinetic in the industrial LWR fuels. From the overall PWR data (figure 3), the initiation threshold determined from EPMA measurements by Lassmann and Walker [42] was ranging from 60 to $75 \mathrm{GWd} / \mathrm{MtU}$. However, the determination of the local burn-up in this case is not so accurate as in the HBRP samples. We have also to account for two other difficulties: a radial instantaneous fission density profile very steep and therefore inaccurate in the rim zone, and an unknown local constraint. Lately from a very fine analysis of a high burn-up fuel performed at TUI, M.Kinoshita [46] gives a probably more accurate threshold around $7 \%$ FIMA (about $70 \mathrm{GWd} / \mathrm{MtU}$ ).

Concerning the temperature threshold for rim formation

Table 1. Comparative Presentation of the Instantaneous Fission Density of the HBRP Samples with the Industrial Fuels

\begin{tabular}{|c|c|c|}
\hline Samples final BU & Power density W/cm ${ }^{3}$ & Fission density fissions $/ \mathrm{cm}^{3} / \mathrm{s}$ \\
\hline $100 \mathrm{GWd} / \mathrm{MtU}$ & 2020 & $6.3210^{13}$ \\
\hline $75 \mathrm{GWd} / \mathrm{MtU}$ & 1520 & $4.7410^{13}$ \\
\hline $55 \mathrm{GWd} / \mathrm{MtU}$ & 1110 & $3.4810^{13}$ \\
\hline $35 \mathrm{GWd} / \mathrm{MtU}$ & 710 & $2.2110^{13}$ \\
\hline PWR fuel $220 \mathrm{~W} / \mathrm{cm}$ & 420 & $1.3110^{13}$ \\
\hline PWR fuel178 W/cm & 340 & $1.0610^{13}$ \\
\hline MOX Pu clusters $178 \mathrm{~W} / \mathrm{cm}$ & 730 to 1100 & 2.3 to $3.410^{13}$ \\
\hline
\end{tabular}


in LWR fuel $\mathrm{UO}_{2}$ pellet, M.Kinoshita [46] confirms a value of $1100^{\circ} \mathrm{C}$. The limit of the restructured zone was found to be related to the starting of the high fission gas release zone.

\subsection{The Effect of the Fission Density and of the FP}

The local instantaneous fission density is obviously one important parameter for HBS transformation. Each fission provides generally two high-energy fission fragments, with an initial kinetic energy ranging from 60 to $90 \mathrm{MeV}$, high energy neutron carrying around $5 \mathrm{MeV}$

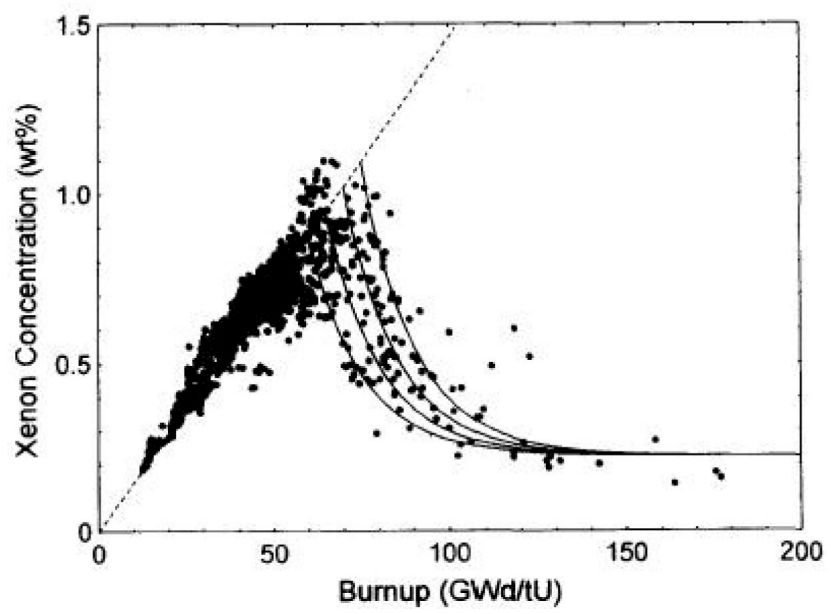

Fig. 3. EPMA Xenon Detection Versus Local Burn-up in PWR $\mathrm{UO}_{2}$ Fuel Pellets (Lassman and Walker [47]) and alpha, beta and gamma radiations. Fission fragments are progressively slowed down first by ionisation of the atoms along their tracks and then by collision cascades with the nuclei of the matrix (Soullard [14]) (figure 4).

J.Soullard [14] has evaluated that about 26500 Frenkel Uranium vacancy-interstitial pairs are created per fission and 72700 oxygen vacancy-interstitial pairs. This means that in a standard fuel operating around $220 \mathrm{~W} / \mathrm{cm}$ each atom $(\mathrm{U}$ or $\mathrm{Pu})$ is displaced almost 0.4 times a day. In the rim, it is nearly one time per day. It is three times higher for oxygen. For the HBRP samples, it gives respectively $0.68,1.0,1.45$ and 1.93 displacements per metallic atom and per day for the 35, 55, 75 and $100 \mathrm{GWd} / \mathrm{MtU}$ samples.

Most of the defects are instantaneously recombined within $10^{-11} \mathrm{~s}$, and only 5000 metallic pairs are remaining after the fission (J.Soullard [14]). The overall process, from the fission event to the fission products stabilization, lasts about $10^{-4}$ second. These remaining defects are able to progressively recover if the thermal activation is high enough, or with the energy brought by a new fission event. Therefore there is a competition between defects' creation and defects' recovering, depending essentially upon the local temperature and the local fission density. The number of defects created is nearly proportional to the fission density. However, it is possible that a higher fission density doesn't mean necessarily a much higher accumulation of defects due to recovery rate.

Even if the defect accumulation is not directly proportional to the instantaneous fission density, this gives understanding to the dependence of the temperature threshold with the local fission density.

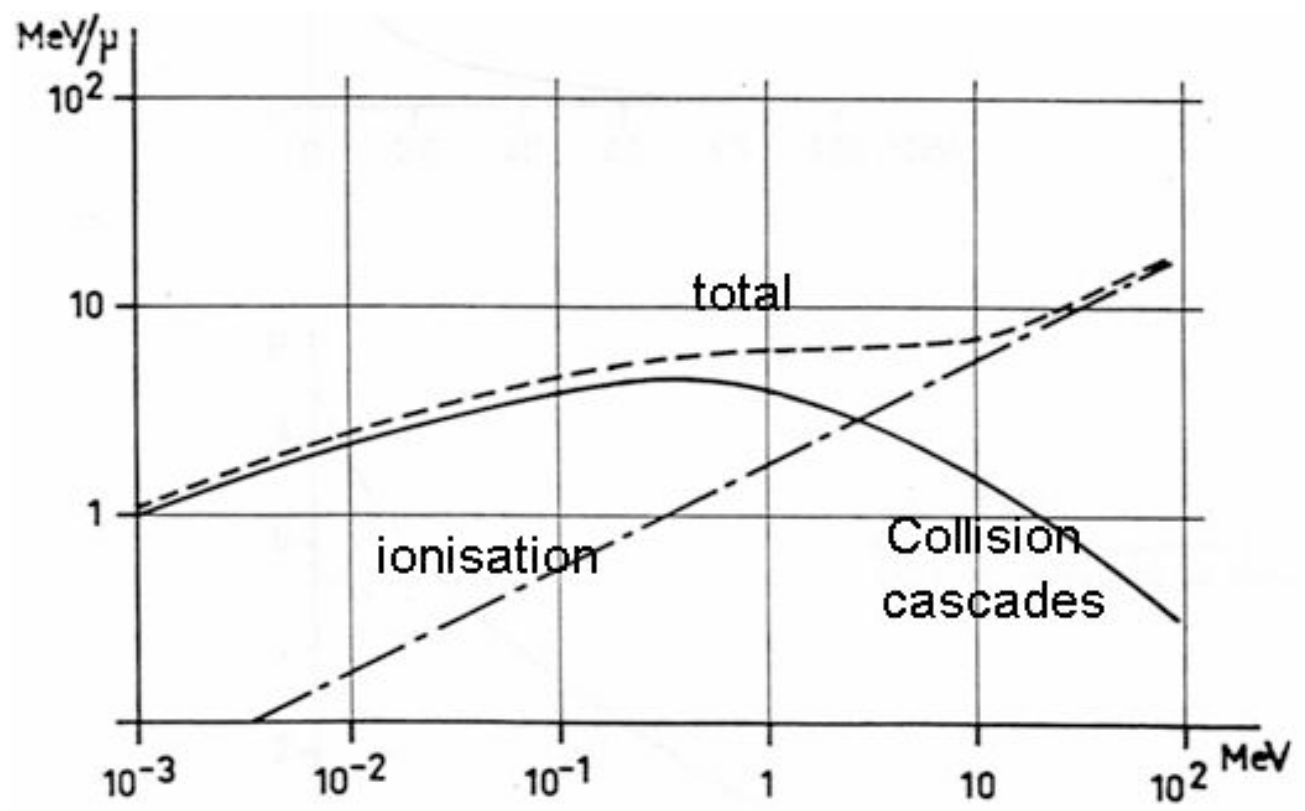

Fig. 4. Fission Fragments Energy Loss 
Another aspect is the role of the fission products stabilized in the fuel matrix, inducing local lattice distortions. These fission products are potential crystal defects, even if they are in solution. Trying to demonstrate the Plutonium effect on HBS transformation, Noirot [15] points out in a MOX fuel the $\mathrm{UO}_{2}$ matrix next to agglomerate, having nearly the same fission product concentration than the cluster totally restructured. This $\mathrm{UO}_{2}$ matrix has no discernable initiation of the HBS structure. He concluded on the evidence of an effect of the Plutonium concentration to accelerate the HBS process. The presence of Plutonium modifies probably the oxygen distribution in the cluster and therefore the local material chemistry.

However, the interpretation given is not straightforward. The high fission product concentration in the $\mathrm{UO}_{2}$ matrix, next to the Plutonium cluster is mainly due to the fission fragment implantation in the matrix. In other words, the flux of fission products generated in the Plutonium cluster is implanted in the $\mathrm{UO}_{2}$ matrix surrounding the Plutonium cluster. Assuming an average free path of $7 \mu \mathrm{m}$, the kinetic energy deposit of the fission fragments during its interaction with the overall material is shared between the cluster and the surrounding matrix. When the fission fragment reaches the cluster limit, it has already lost most of its energy. This means that for the same amount of fission product accumulation, the total energy deposit in the surrounding $\mathrm{UO}_{2}$ matrix is lower than in the Plutonium cluster. Therefore, this could be also an explanation for the delay observed in the $\mathrm{HBS}$ formation in the $\mathrm{UO}_{2}$ matrix.

\subsection{About Dislocations}

Fission energy is therefore the main energy provided in the nuclei and particles mobility process. However these fission spikes are happening randomly and have no reason to induce a specifically ordered reorganization of the material. In order to induce the mobility and the redistribution of nuclei in a particular way, the material needs strain and stress gradients at the restructuring scale. From TEM observations, this scale is ranging around 100 to $500 \mathrm{~nm}$ (figure 5).

The TEM pictures performed by T.Wiss in TUI or K.Nogita in Japan on high burn-up fuels above 45 $\mathrm{GWd} / \mathrm{MtU}$, show dislocations progressively tangling-up (see example on figure 5). For burn-up lower than 45 $\mathrm{GWd} / \mathrm{MtU}$, K.Nogita [17] gives the following correlation to evaluate the dislocations density evolution:

$$
\log \left(\rho_{\text {disloc }}\right)=2.210^{-2} B U+13.8
$$

Where $\rho_{\text {disloc }}$ is the dislocation density expressed in $\mathrm{m} / \mathrm{m}^{3}$ and BU is the local burn-up in GWd/MtU. Saturation is observed around $5.810^{14} \mathrm{~m} / \mathrm{m}^{3}$. This doesn't mean that no more dislocations are created but that they are piling up, creating a kind of entangled network. This limitation in the density of dislocations clusters could be probably related to the established density of precipitates on which the dislocations are fixed. This also means that the probability for a fission product to stabilize is likely higher at the location where dislocations are.

The permanent increase of the material entropy, the relatively low evolution of the lattice parameter with burnup and the recovery of the lattice parameters observed as soon as the material is restructuring, suggest that most of the fission products are not uniformly distributed. In addition the relative stabilization of both the material thermal conductivity degradation even after annealing and of the elastic properties degradation when rim structure initiates tends to demonstrate that the limit of solubility is reached. Where are these fission products located? Are they really homogeneously distributed? Probably not because the presence of other fission products must change the local incorporation energy in its surrounding. One can expect that a large part of fission products could agglomerate. Dislocation tangles are probably mainly constituted of fission products. Nearly $30 \%$ of these fission products are gaseous fission products (xenon and krypton). Moreover, because of decay chains, these gaseous species must be associated to other elements. For example, xenon is always accompanied by tellurium, cesium, barium and iodine. The dislocations' tangles should be therefore constituted of complex compounds. At the present time, such a proposed assumption cannot be experimentally evidenced, having no way to characterize the fission products distribution at such a scale $(0.2$ to $1 \mu \mathrm{m})$. Very high energy XRD could perhaps allow detection and identification of these compounds. Figure 5 shows a distance between dislocations around 0.2 to $0.4 \mu \mathrm{m}$ (200 to $400 \mathrm{~nm}$ ).

These dislocation tangles induce local energy concentrations, proportional to the local number of dislocations. J.Jonet [18] studied in his $\mathrm{PhD}$ work the

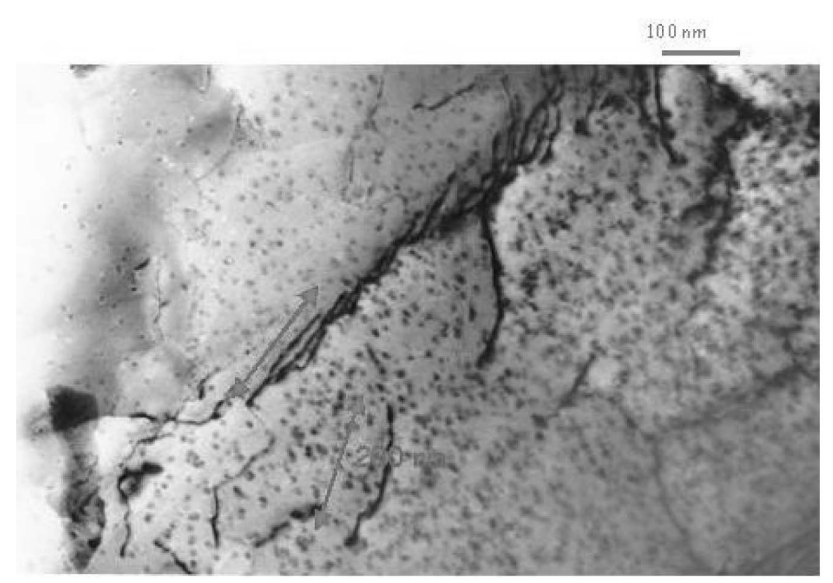

Fig. 5. TEM on a HBRP Sample $35 \mathrm{GWd} / \mathrm{MtU}$

Dislocations' Spacing is about 100 to $200 \mathrm{~nm}$. (HBRP [16]) 
effect of different dislocations configurations on the stored energy, and their effect on the microstructure. A consequence is that the entangled dislocations are creating a stress field in their direct neighbourhood, which locally increases the stress/strain gradient.

Mobility of vacancies should therefore be enhanced towards dislocation clusters in order to release the local stress induced by local gas accumulation. This favours bubble growth at dislocation location (figure 6). Bubbles are stabilized by their internal gas pressure.

This means that vacancies are moving towards gas accumulation spots and not the opposite. As the vacancies mobility is much higher than gas atoms, the apparent gas diffusion rate used in modelling has to be be enhanced of two decades at short distance. But the reality is that the

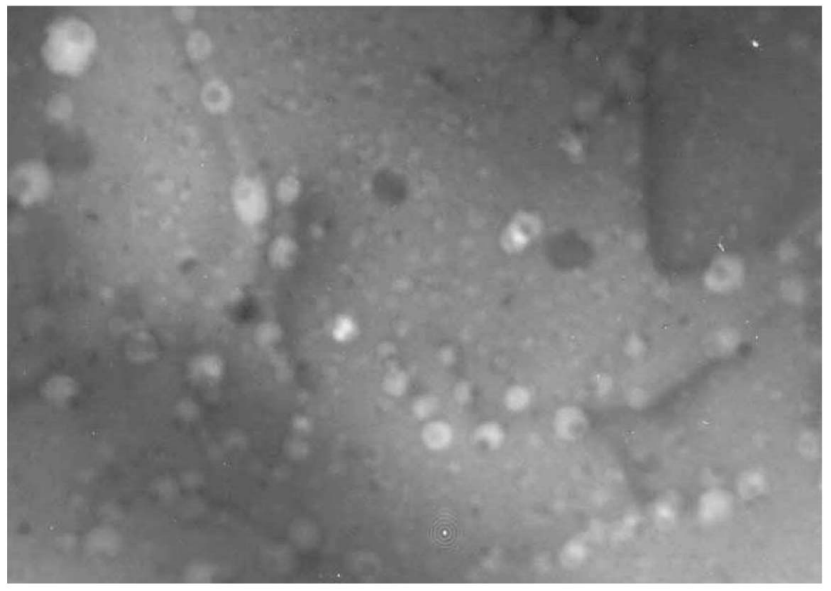

Fig. 6. TEM on a HBRP Sample $35 \mathrm{GWd} / \mathrm{MtU}$

Growing Bubbles Aligned along Dislocations Tangles

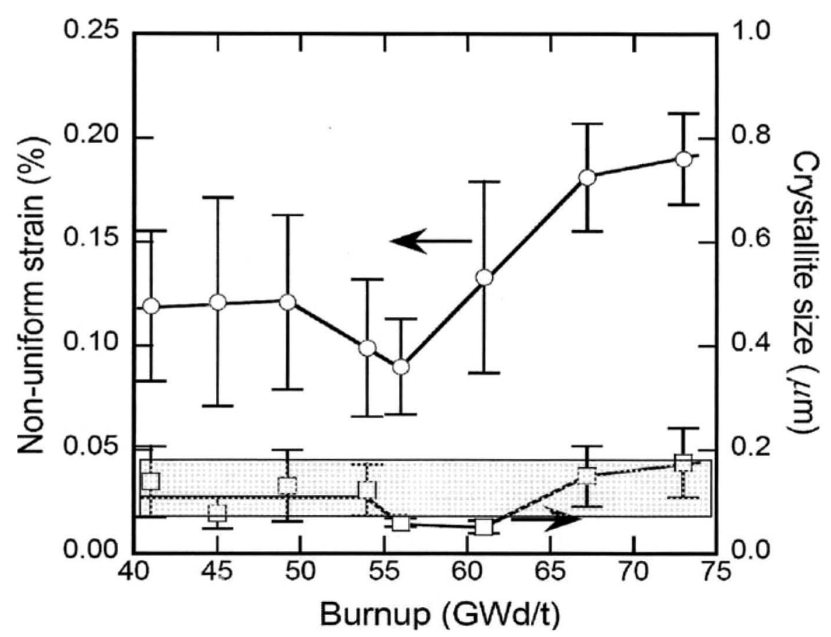

Fig. 7. Evolution of the Non-uniform Strain and the Average Crystallite Size with Local Burn-up (Amaya and Nakamura [48]) gas atoms are not moving. Dynamic molecular calculations could probably, confirm the high stability of gas atoms close to dislocations.

\subsection{A Transformation at Quasi-constant Volume}

Concerning the grain subdivision mechanisms, Masaki Amaya and Jinichi Nakamura [48] are providing useful information, using fine XRD analysis on a representative HBS transformation sampling, ranging between 40 and $66 \mathrm{GWd} / \mathrm{MtU}$. The shift of the diffraction angles is giving the crystal lattice expansion, and the widening of the diffraction's spikes the status of the grain subdivision and the grain-to-grain constraint (William and Hall [20,21] method). The lower is the fuel local temperature; the larger is the spikes width. Even after a heat treatment at $1600{ }^{\circ} \mathrm{C}$, the spikes width remains still enlarged. J.Nakamura shows that the crystallites size saturates around $200 \mathrm{~nm}$ for local burn-up higher than $67 \mathrm{GWd} / \mathrm{MtU}$ (pellet average burn-up is $57 \mathrm{GWd} / \mathrm{MtU}$ ). This is consistent with the value of $300 \mathrm{~nm}$ reported by M.Kinoshita [46].

The non-uniform strain evaluation increases from 0.1 to $0.2 \%$ with increasing grain subdivision (figure 7 ). During fuel restructuring, J.Spino [11] shows that the lattice parameter is decreasing in the same time of $0.1 \%$. This means that the transformation could be considered as happening at nearly constant volume.

It is confirmed in figure 8 where J.Nakamura gives the evolution of the local stored energy as measured in his own experimentations. These results also suggest that the stored-energy saturates when the grain subdivision phase starts. The increase of the stored energy between 55 and $65 \mathrm{GWd} / \mathrm{MtU}$ could be related to the attainment of the solubility limit we have already mentioned, or a

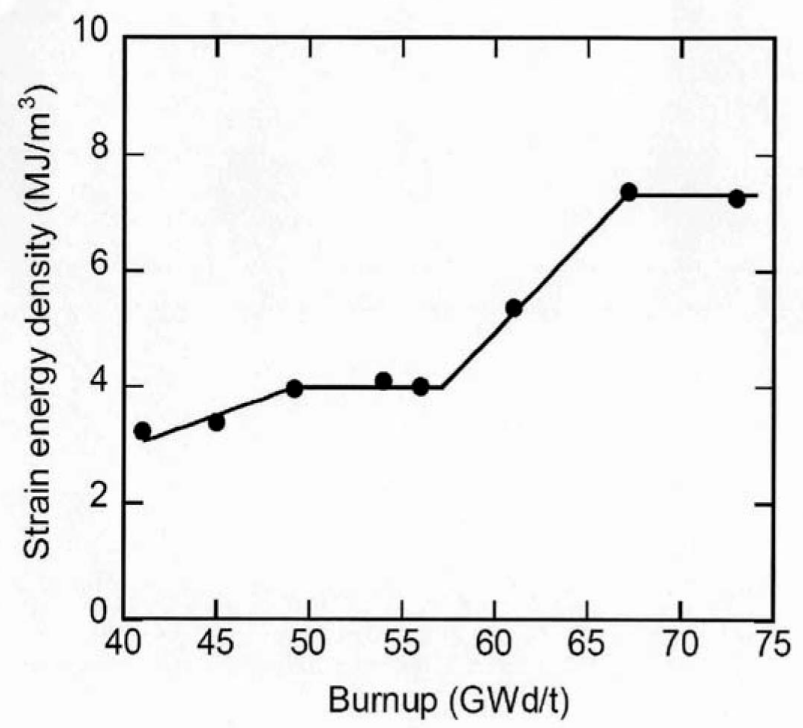

Fig. 8. Evolution of the Average Stored Energy Density (Amaya and Nakamura [48]) 
threshold in the oxygen buffering.

The decrease of the non-uniform strain around 55 $\mathrm{GWd} / \mathrm{MtU}$ is, up to now, not explained, but could probably be in relation with the increase of the lattice parameter reported by J.Spino [11] in the "sub-rim" region.

\subsection{Effect of the Local Constraint}

Because the material trend is swelling, there are two kinds of constraints to be considered: a macroscopic hydrostatic external constraint and the material internal constraint.

Concerning the macroscopic constrain, it is due to the structure interaction i.e. axial pellet-to-pellet interaction, pellet-cladding interaction and the global fuel swelling. Due to the cylindrical shape of the pellet, the thermal expansion leads to a pellet edge hoop strain in tension and a pellet centre in compression. However as burn-up and associated swelling proceed, the pellet edge is progressively in compression due to an accelerated swelling, as the pellet edge burn-up increases faster (self-shielding effect of ${ }^{238} \mathrm{U}$ ). Moreover, the axial and radial pellet clad interactions amplify these phenomena. In case of high stress, creep deformation could relax the material. Unfortunately, no data are available at present time on the fuel creep properties at low temperature and high constraint; however we cannot ignore that an axial flow was evidenced in the rim region of commercial fuels (Guedeney [49]).

In fact, nuclear fuel material is a poly-crystalline, meaning that it must be regarded as constituted of two materials: the crystals (intrinsic properties) and the grain boundaries. As burn-up proceeds, many fission products, solid and gaseous, accumulate in the grain boundaries preventing the gas from diffusing by itself towards the free volumes (P.Van Uffelen [22]) of the rod. Fission gas bubbles are formed at the grain boundary. Grain swelling accommodation depends then upon the evolution of the grain boundaries properties. In this condition the inner grains constraint is depending upon the capability of the grain boundaries to accommodate the swelling. Decreasing the average grain size increases the number of grain boundaries therefore the capacity of the fuel to accommodate the swelling.

Increasing matrix hydrostatic compressive stress probably reduces the fission products free path, and therefore the fission products mobility. It was shown that in case of a delayed HBS transformation like presented in the N118 BR3 fuel rod (J.Spino [9-11]), it was associated to a higher density of micrometric bubbles with a smaller size (presentation D.Baron [24] at the TUI HBS workshop in June 2004): $25-30.10^{16}$ bubbles $/ \mathrm{m}^{3}$ instead of $5.10^{16}$ bubbles $/ \mathrm{m}^{3}$ usually measured. The formation of a higher density of small bubbles suggests a smaller mobility of atoms. However an addition of Chromium oxide can counterbalance this matrix stress effect by increasing the initial number of point defects and therefore the atoms self-diffusion, as presented in the following sub-chapter.

\subsection{The Effect of the Initial Grain Size}

The contradictory results obtained about the grain size effect on HBS formation can be explained by the manufacturing technique used to enlarge the grains. There are indeed several techniques:

a) Increasing the sintering time enlarge the maximum grains size in $\mathrm{UO}_{2}$ by $30 \mu \mathrm{m}$.

b) Using additives like aluminum-silicates, inducing liquid phases at grain boundaries at sintering temperatures enlarge the average grain size from 30 to $65 \mu \mathrm{m}$.

c) Using trivalent additives promoting atomic self-diffusion in the grains during the sintering phase increase the grain size from 30 to $100 \mu \mathrm{m}$ (figure 9).

The use of chromium oxides combines b) and c), with the formation of a liquid $\mathrm{CrO}$ phase at the grain boundaries if the proper thermodynamic sintering conditions are met. The grain growth is then a combination of an auto-diffusion enhancement and acceleration due to the $\mathrm{CrO}$ liquid phase. Depending upon the $\mathrm{Cr}_{2} \mathrm{O}_{3}$ initial content, the solubility limit is overtaken or not initiated at all, then eventually precipitates. This can then favour fission products or dislocations trapping.

A main conclusion reported by NFD is that a large grain size delays the HBS transformation (K.Une [23]). The explanation proposed is that the HBS transformation is initiated at grain boundaries essentially because vacancies are provided from grain boundaries, therefore a reduction of the grain boundaries surface delays the HBS process. In this case large grains were obtained using techniques a) and b).

These conclusions are consistent with observations we have performed on a BR3 fuel rod in TUI (J.Spino [911]) with an average pellet burn-up of $68 \mathrm{GWd} / \mathrm{MtU}$ and an initial grains size of $17 \mu \mathrm{m}$ obtained by technique a). The grain subdivision was greatly delayed despite a local burn-up in the pellet rim ranging from 80 to $100 \mathrm{GWd} / \mathrm{MtU}$.

On the contrary, large grain fuel pellets manufactured

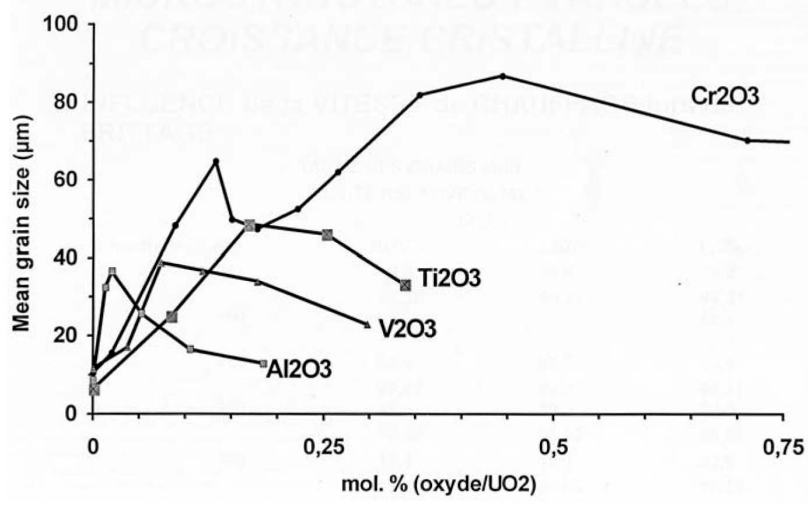

Fig. 9. Evolution of the Average Grain Size Versus Additives Content - Sintering Temperature $1700{ }^{\circ} \mathrm{C}$ - L.Bourgeois [26] 
with Chromium additive exhibits an accelerated HBS transformation process, likely explained by a consequence of the trivalent additive on the gaseous fission products free path as soon as the irradiation starts. The oxygen sublattice perturbation and cation charges have an important influence on the atomic self-diffusion. The formation of chromium nano-precipitates during the first irradiation period, could also favour an early precipitation of fission products.

On the other hand, the large grains obtained with chromium additive in EDF industrial power plants shows that HBS transformation is not always departing from grain boundaries (figure 10). It seems to depart randomly, depending upon very local conditions. This has also been confirmed on standard fuel where average grain size is about $10 \mu \mathrm{m}$ (J.Noirot [15]).

We can definitely conclude that enlarging grain size tends to delay HBS transformation. On the basis of our discussion in the previous sub-chapter it is shown that grain boundaries play the role of mechanical absorber. It can be expected that the constraint is globally higher in large grains, as enlarging grains reduces the number of grain boundaries.

\subsection{The Effect of an Initial Micrometric Porosity}

Introducing chapter II it was mentioned that micrometric bubbles appear before the polygonisation process. It is considered that the round sub-grains (50 to $150 \mathrm{~nm}$ ) observed on the bubble inner surface is related to a surface relaxation mechanism as suggested by N.Lozanno [12]. Polygonisation is a bulk mechanism leading to polyhedral

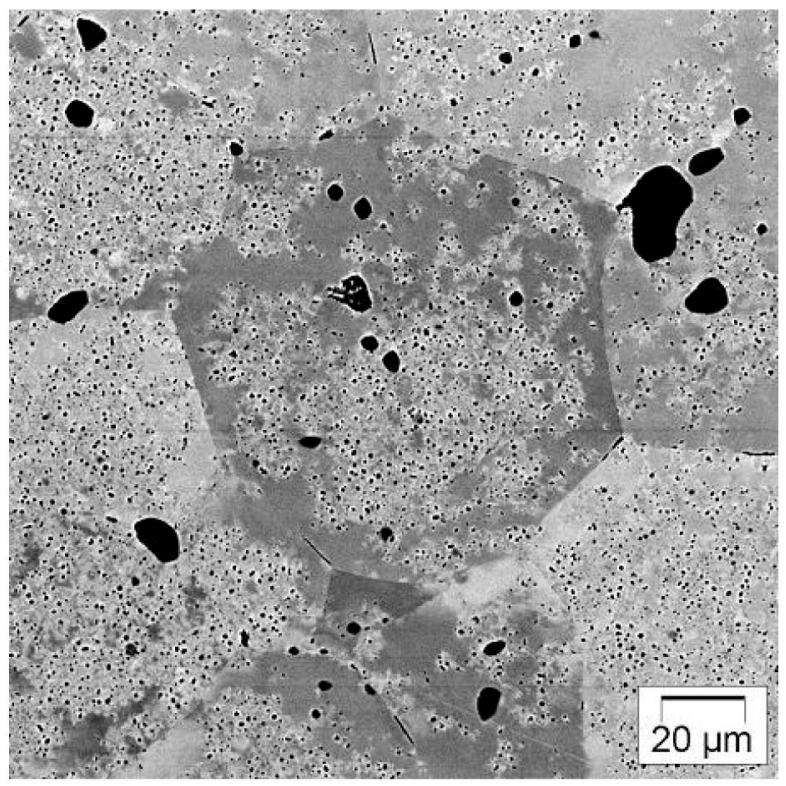

Fig. 10. HBS Transformation is Initiated Randomly in the Grain and not Systematically from Grain Boundaries grains 200 to $600 \mathrm{~nm}$. The micrometric gas bubble density achieved in the first stage could have an effect on the micrometric stress fields (energies) between the micropores, and then on the dislocations sources activity. The presence of this bubble feature reduces the global thermal conductivity but also decreases the global toughness of the material.

The Studsvik laboratory within the HBRP_NT project proposed an interesting experiment (M.Kinoshita [25]). A fuel slice $1 \mathrm{~mm}$ thick was cut from a $61.4 \mathrm{GWd} / \mathrm{MtU}$ industrial fuel pellet and re-irradiated in quasi isothermal conditions $\left(400\right.$ to $450^{\circ} \mathrm{C}$ ) in the $\mathrm{R} 2$ reactor up to 80.9 $\mathrm{GWd} / \mathrm{MtU}$ (figure 11), in a specific device (SRIP). The disk was sandwiched between two Molybdenum pellets in order to limit the radial temperature gradient.

The post irradiation examinations gave the following information:

a) As expected, the restructured zone, already existing in the initial pellet, is enlarged at the disk rim.

b) HBS process is underway at mid radius of the disks. On the original pellet, this "densification zone" does not exhibit any initiation of the HBS structure.

c) Near the disk centre, the material is totally restructured. On the pellet before re-irradiation, because of the base irradiation, thermally activated gas precipitation is
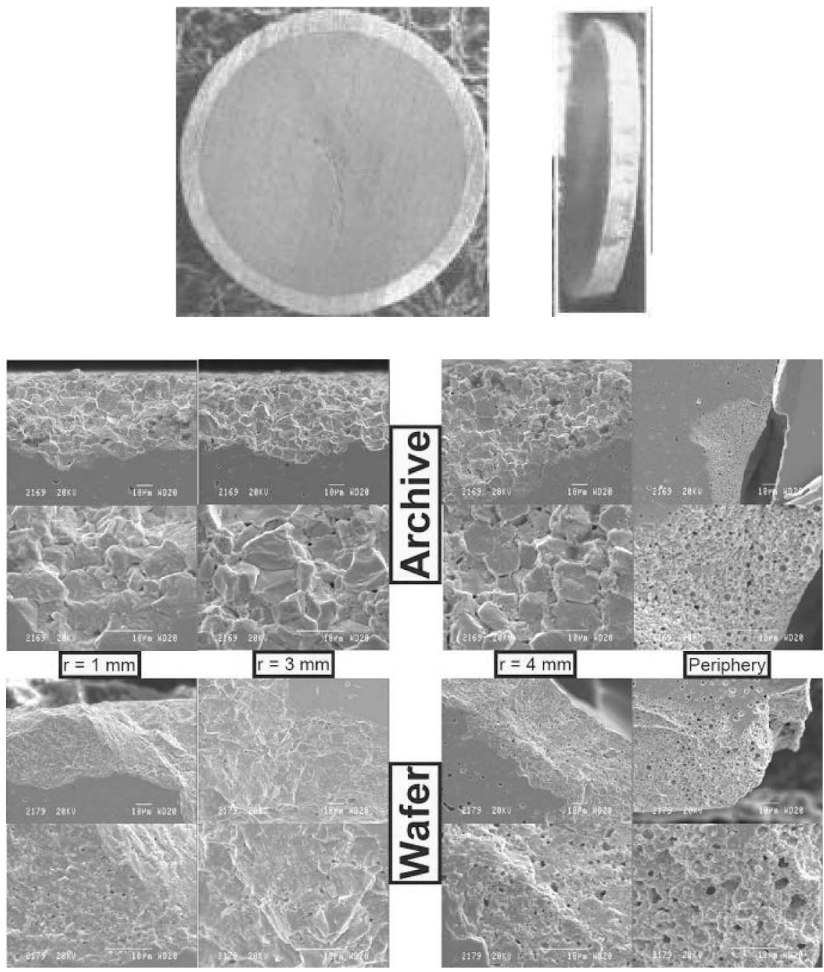

Fig. 11. Fuel Disk Cut in a $61.4 \mathrm{GWd} / \mathrm{MtU}$ Industrial Fuel Pellet and Re-irradiated in Quasi Isothermal Conditions ( 400 to $450^{\circ} \mathrm{C}$ ) in the R2 Reactor Up to $80.9 \mathrm{GWd} / \mathrm{MtU}$ 
observable. The gas bubbles are very similar in density and size to what is observed in the cold area of the pellet during the HBS transformation process.

Comparing the centreline behaviour with the midradius observations, it can be concluded that the preexistence of a large density of micrometric pores enhance the grain subdivision at low temperature; whatever is the origin of the pores.

\subsection{HBS Localization in the Fuel Pellet}

In $\mathrm{UO}_{2}$ fuel, the HBS restructuring initiates at the pellet rim. The HBS transformation threshold is reached at this location because of the Uranium 238 self shielding effect leading to a higher local fission rate and a quicker burnup accumulation, but also because the local temperature is low enough to avoid any consequent thermal restoration of irradiation defects. When the pellet average burn-up is increasing, the HBS structure tends to propagate toward the centre.

The radial power generation distribution is almost flat in the major part of the pellet, apart in the neutronic selfshielding region at the pellet edge. It is similar for the burnup radial profile, almost flat along the radius and increasing sharply in the self-shielding region. Then, in abscence of local burn-up gradient, the secondary local parameters such as constraint and temperature will determine HBS initiation moment and location. There is therefore no reason to propagate systematically the HBS structure from the rim zone toward the pellet centre. It can be expected that HBS formation conditions could be met at mid radius

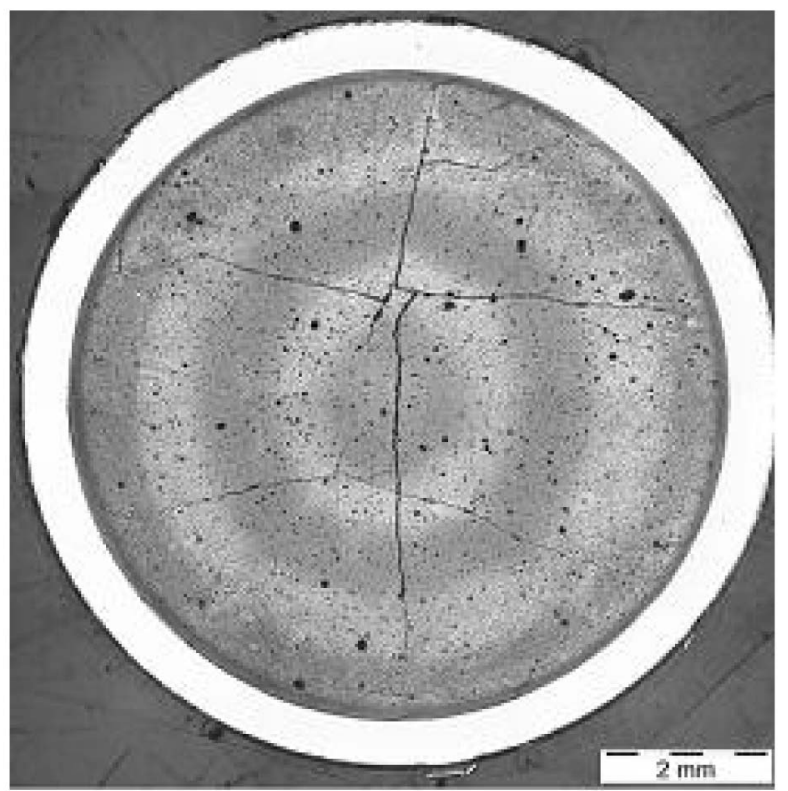

Fig. 12. UO2 Irradiated up to $80 \mathrm{GWd} / \mathrm{MtU}$ Pellet Average after 7 Cycles in the GRAVELINE 5 EDF Reactor before it is in the "sub-rim" region.

Even if the HBS structure is considered almost as a non-thermal mechanism, a minimum thermal activation could favour short distance restructuring. For example, at mid radius (between 0.4 and $0.6 \mathrm{R}$ ) where the temperature is usually in the range $700-800^{\circ} \mathrm{C}$, the thermal restoration is low enough to promote defects accumulation, accounting for a standard fission rate of $10^{13} \mathrm{fiss} / \mathrm{cm}^{3} / \mathrm{s}$. In addition between 0.4 and $0.6 \mathrm{R}$, the macroscopic constraint is very low during the whole irradiation.

Standard $\mathrm{UO}_{2}$ fuel rods were irradiated in the EDF GRAVELINES 5 reactor, for 6 and 7 cycles. A loss in xenon detection was found on EPMA analysis in the rim region, but also between 0.65 and $0.8 \mathrm{R}$. Examinations of this location combining SIMS analysis and EPMA have shown an important intra and inter granular precipitation of fission gas in micrometric bubbles. The precipitation zone at mid radius can also be observed on the largescale ceramography shown in figure 12 . It doesn't correspond to a thermal fission gas release zone. This observation is very similar to the observation made in the sub-rim region with the difference that the loss of detection is higher. It suggests that the process is more advanced. The HBS process is probably initiated, being still in the plane defect state.

Similar observations were made in $\mathrm{UO}_{2}$ fuel with chromium additives, but at lower burn-up (60 GWd/MtU), confirming an accelerated process in this kind of fuel.

\subsection{Thermal Annealing Tests}

The HBS transformation leads to the precipitation in the micrometric bubbles of nearly $80 \%$ of the fission gases produced. Indeed, a SIMS analysis is able to recover most of gases generated in the restructured zones. The fission gas release during standard base irradiation in PWR power plants is expected less than 8 to $10 \%$ (J.Noirot [27]).

Annealing tests are usually performed on irradiated fuel samples to measure the fission gas release according to temperature. Data collected within the HBRP (Kinoshita [5]) and the HPRP_NT (Kinoshita [25]) have shown a non-typical behaviour of the restructured samples. On a non-restructured material, the fission gas release is increasing progressively with temperature. In the case of the HBS structure, a first release is observed as soon as the temperature is beyond the irradiation temperature threshold. The material is meta-stable and tends to release part of its energy by a limited cracking of the sample, accompanied by a limited gas release, 5 to $10 \%$ maximum. Then, increasing the temperature no further release is happening up to a temperature threshold evaluated around $1230^{\circ} \mathrm{C}$ for $\mathrm{UO}_{2}$. At this threshold temperature, the overall gas precipitated in the bubbles is quickly released. As this threshold is very reproducible from one fuel to the other, the interpretation is that this temperature corresponds to a phase transformation. 


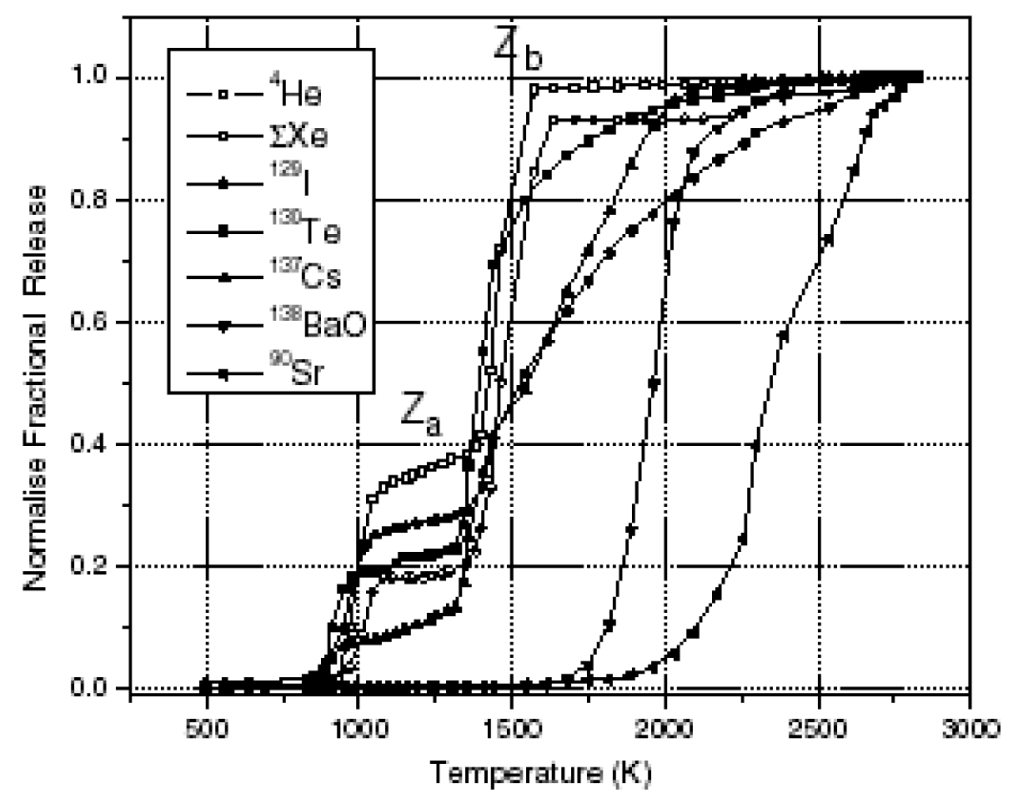

Fig. 13. Fission Product Release During Laboratory Annealing of a very High Burn-up Fuel Specimen (Hiernaut [39])

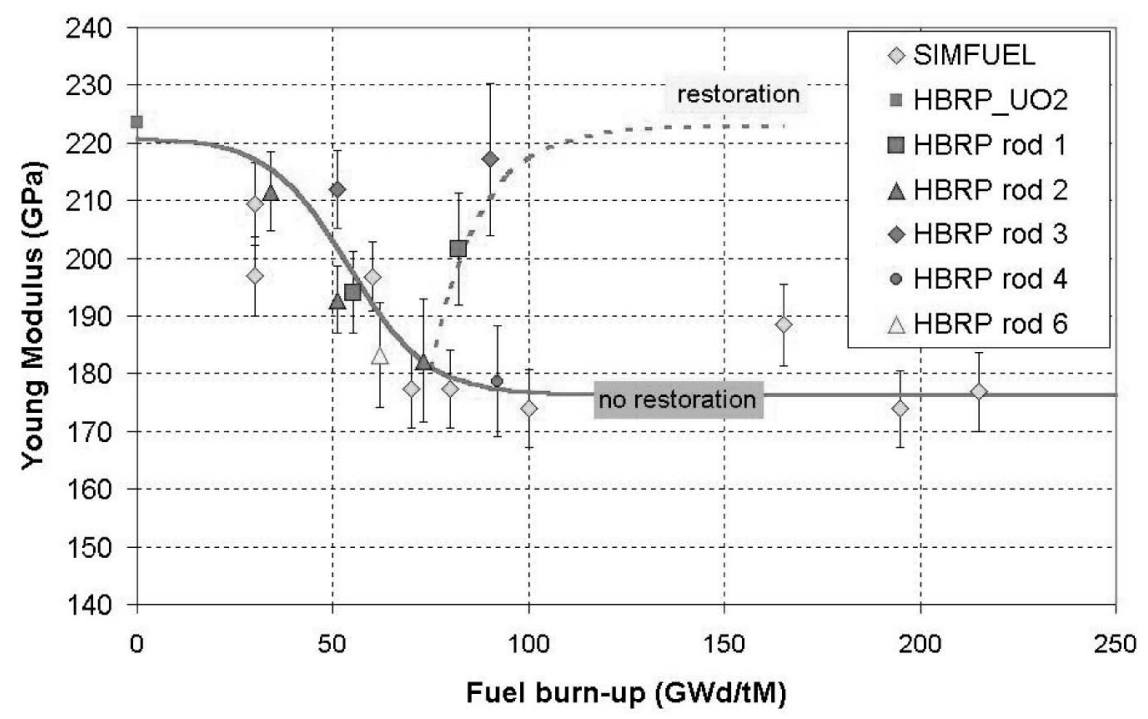

Fig. 14. Evolution of the intrinsic elastic modulus with burn-up (D.Baron [30])

Similar experiments were performed in CEA on MOX fuels samples. For the MOX fuels, the threshold temperature was lower than in $\mathrm{UO}_{2}$ and evaluated around $1140^{\circ} \mathrm{C}$. This is likely due to a different distribution of the fission products yield between Plutonium and Uranium 235. It can be expected that the chemical species, and mainly the phases formed are different in $\mathrm{UO}_{2}$ fuel and in MOX fuel mostly in the Plutonium agglomerates.

There are two possible explanations on the non inter- linkage of the pores below the threshold temperature:

- The presence of a viscous phase in the sub-grain boundaries, stable up to the threshold temperature or,

- A change in the overall oxygen distribution at the threshold temperature, which leads to a modification of the overall oxygen potential.

It was pointed out by J.Spino [28] that the evolution of the oxygen potential of the fuel could be one of the key points of the HBS transformation. In their work J.P 
Hiernaut et al [39] have also shown that part of the cesium, iodine and tellurium was released simultaneously with xenon around 1500K (Figure 13). This suggests a partial correlation between these species in terms of release mechanism around this temperature threshold.

There is also an effect of the sample constraint on the fission gas release behaviour during the annealing test. K.Une and S.Kashibe [29], have shown that heating restructured samples under pressure can strongly inhibit fission gas release. Release is obviously re-activated as soon as the pressure is dropped.

\subsection{Elastic Properties}

EDF R\&D developed in the period 1996-2000 an acoustic device with the Montpellier University to measure the evolution of the local elastic properties (D.Baron [30]). This device was introduced in the TUI hot cells to acquire measurements on irradiated samples. The results obtained on HBRP samples, on SIMFUELS samples and on a BR3 fuel pellet (fuel rod N118) available in the TUI hot cells are presented in figure 14. It shows a non-linear decrease of the elastic properties with the increase of fission products in solution and then, a stabilisation around 60-70 GWd/MtU corresponding probably to the limit of solubility of the fission products in the matrix.

Concerning the restructured samples, the material transformation is accompanied by a restoration of the intrinsic elastic properties. Simultaneously, it was demonstrated that the intrinsic fuel conductivity degradation is slowing down (C.Ronchi [31]), and the lattice parameter partly restored (J.Spino [11]). This looks like a cleaning of the fuel matrix within the crystallites during the grain subdivision phase.

\section{MECHANISM FOR THE HBS TRANSFORMATION}

Several recent models were developed or are still in development such as the V.Likhanskii [32] model based on the mathematical model proposed by M.Kinoshita [33], the J.Rest [34,35] model or the model developed in START3 by G.Khvostov [36]. These improved models consider that the HBS transformation is initiated on grain boundaries and that gas precipitation and grain subdivision propagation are simultaneous phenomena. It was shown that gas precipitation and grain subdivision propagation are two distinct phenomena. Most of the time, the two processes are following each other very quickly. However, some experimental observations have demonstrated that the second process could be strongly delayed. I.L.F.Ray and H.J Matzke reported in the JNM an observation on a high burn-up rim-type structure in advanced PlutoniumUranium carbide. The SEM picture given in figure 2 of their document (Ray [50]) shows clearly that if the first stage is achieved for a burn-up of $85 \mathrm{GWd} / \mathrm{MtU}$ (gas precipitation and facetted bubbles), the second stage (grain subdivision) is not observed: different materials lead to different thresholds.

In most models, we have also to assume a diffusion coefficient for fission gases, two orders of magnitude higher than normal. In the V.Likhanskii model such an assumption is made in the vicinity of the dislocations.

In the following we propose a possible mechanism for the HBS transformation compatible with all the discussions reported in chapter II. This is a four phases mechanism.

\subsection{Phase 1: Construction of a Periodic Network}

As soon as irradiation proceeds, a large number of dislocation loops are created by accumulation of interstitial defects. Katsumi Une [17], suggests that larger scale dislocations are built by accumulation of these dislocation loops, up to about $45 \mathrm{GWd} / \mathrm{MtU}$. Above this burn-up, the dislocations are entangling in a basic network as shown in the TEM picture on figure 5. All this process is happening before any modification in the material texture happens (piece of crystal disorientation, sub-grains formation). This progressive dislocations network construction is probably pinned on metallic or ceramic precipitates. Their density defines then the periodicity of the network. The average distance between the entangled dislocations is close to the size of the final sub-grains (about 200-300 $\mathrm{nm}$ ). The periodicity is probably also in relation with a heterogeneous distribution of the fission products, as it is for the oxygen in a non-stoichiometric $\mathrm{UO}_{2}$ (F.Garrido [37]). Frederico Garrido has shown that for symmetry reasons, the oxygen in excess is not randomly distributed but tends to group in particular cells of, "cuboctahedric" type able to embody 14 to 15 oxygen sites instead of 8 . In the NXO program H.G. Geng $[40,41]$ analysed the oxygen ordering of the hyper-stoichiometric state with first principle analysis code VASP. He classified oxygen interstitial configurations according to their energy formation and found that it was possible to find oxygen dimmer (oxygen molecule) in the $\mathrm{UO}_{2+x}$ system.

Dislocations are probably mainly constituted of fission products and oxygen in excess. The term "tangled dislocations" in the case of nuclear fuel ceramics is perhaps not really appropriate as it could be more than a piling of $\mathrm{U}$ or $\mathrm{O}$ defects. The TEM observations show a kind of entangled dislocations, which could correspond to complex or perhaps amorphous phases, explaining the observation of planar defects at this stage. On this assumption, the probability could be higher at such location for fission products to stabilize after slowing down, mainly for the bigger ones. In addition, when reaching the solubility limit of the material, the process could be amplified. This assumed non-homogeneous distribution of the fission products, is not accessible at the actual EPMA mapping analysis scale. The EPMA beam allows investigating, at the best, volumes about one cubic micrometer when the heterogeneities we are speaking of are ranging within 
200 to $500 \mathrm{~nm}$. It should be also noted that for the different decay chains, fission products associations are to be expected such as iodine, xenon, cesium, tellurium and Barium. It means that the formation of complex fission products compounds is favoured where fission products accumulate. The properties of such compounds in terms of elasticity, viscosity or thermal expansion is different from $\mathrm{UO}_{2}$ as studied by J-P.Berton [38] at TUI. As an example, he showed that $\mathrm{Cs}_{2} \mathrm{UO}_{4}$ is easily formed under constraint above $400^{\circ} \mathrm{C}$ and stable up to $800-900^{\circ} \mathrm{C}$. This compound is becoming viscous above $400^{\circ} \mathrm{C}$ with a thermal expansion coefficient $30 \%$ higher than the $\mathrm{UO}_{2}$ one. The compounds formed are certainly more complex than $\mathrm{Cs}_{2} \mathrm{UO}_{4}$, however if these assumptions were confirmed, it should have a consequence on the sub-grain boundaries properties and could then explain the particular fission gas behaviour in HBS material. This behaviour would be then compatible with a phase transformation around $1220^{\circ} \mathrm{C}$. It would also explain that this temperature threshold looks different for MOX fuels $\left(1140^{\circ} \mathrm{C}\right)$.

\subsection{Phase 2: Loss in EPMA Gas Detection}

The lattice distortion induced by tangled dislocations leads to nano-scaled energy gradients, favouring vacancies migration towards dislocations in order to relax these local energies accumulations. The TEM images performed on HBRP samples [16], with a homogeneous burn-up

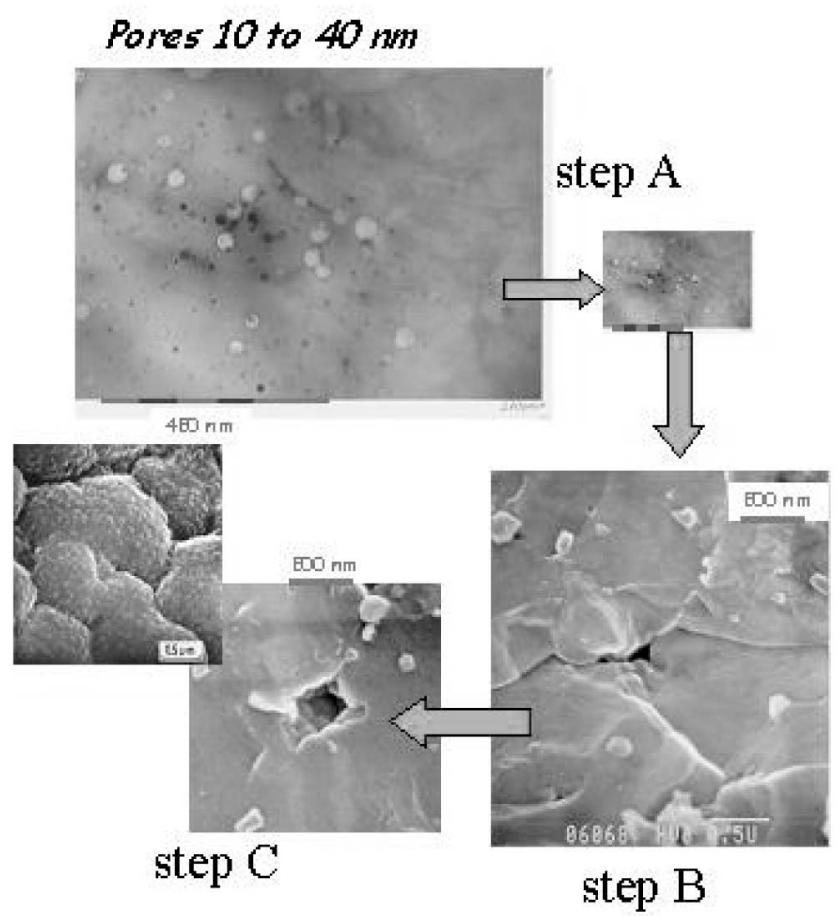

Fig. 15. Bubbles Coalescence Process along Dislocations Clusters Followed by Free Surface Opening Process Accompanied by Grain Surface Subdivision (figures 6 and 15) exhibits nano-bubbles in permanent creation and decay. These bubbles are however able to stabilize and grow as soon as they are pinned on dislocations. Stabilization is due to their high pressurization due to the presence of gas atoms in the disturbed zones, making their destruction difficult. They generate strain fields in their surrounding. The vacancies migration towards krypton/xenon rich zones should then explain the amplification of the apparent gas diffusion coefficients indispensable in the HBS formation models, to properly simulate the intragranular bubbles formation and filling. Their circulation is made locally easy along the dislocation tangles. Models used are expecting a short distance diffusion coefficient two decades as fast as normal diffusion coefficient.

\subsection{Phase 3: Intragranular Nano-bubbles Coalescence and Growth}

These stabilized nano-bubbles, still intragranular, are then growing by a coalescence process along dislocations clusters (figure 15, step 1), leading progressively to an opening of free flat surfaces (figure 15, step B). The generation of free surfaces allows partial relaxation of the local energy through a surface undulation induced by surface diffusion of point defects. This surface diffusion leads to the formation on the pore surface of 50 to 100 nm "round grains" as reported by N.Lozanno [12] et al. Looking closer a minimum of three subdivision levels can be observed, as shown on figure 1. Bubbles tend then to become quasi-spherical due to the internal gas pressurization (figure 15, step C), achieving at the end micrometric sizes.

\subsection{Grain Subdivision Propagation}

The grain subdivision propagation happens mostly after the micrometric porosity formation, as suggested by several observations. Now most specialists agree on the fact that the mechanism involved is a polygonization

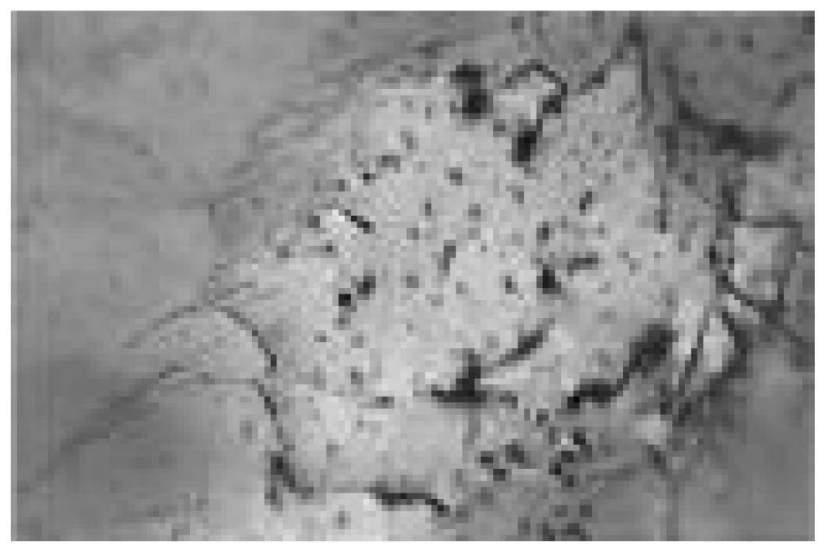

Fig. 16. Dislocation Walls Formation 


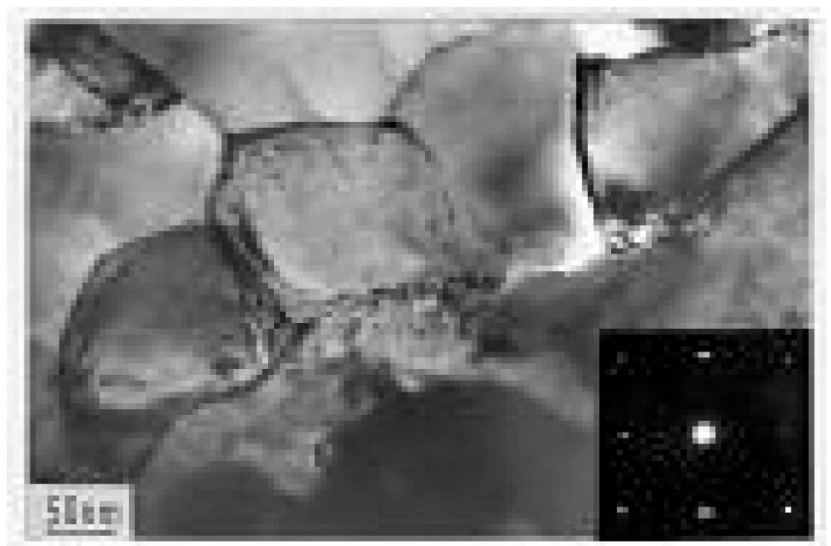

Fig. 17. Low Sub-grain Miss-orientation
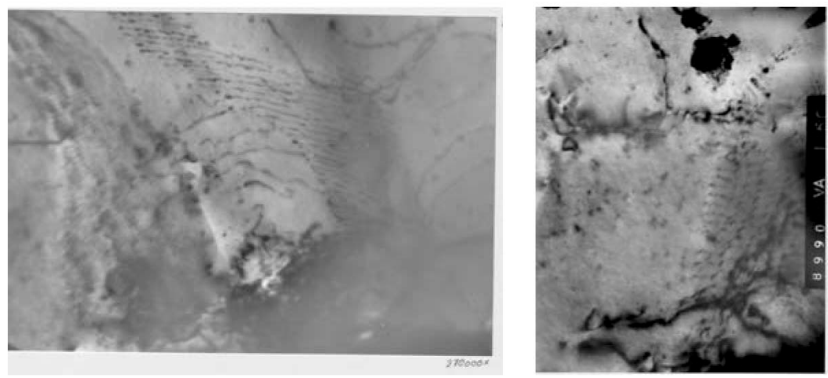

Fig. 18. Increase in Dislocation Generation and Dislocations Piling Process

process, as it can be seen on figure 16. The final grains are large angle grains (figure 17) with low disorientation.

Subdivision kinetic seems to be influenced by the density of micro-pores formed. Delay in grain subdivision was indeed observed in the fuel pellets of the N118 BR3 fuel rod (Spino [9]). In this fuel, the as fabricated porosity has a density around $2510^{16}$ bubbles $/ \mathrm{m}^{3}$ when in standard fuels the usual porosity density is 5 to $1010^{16}$ bubbles $/ \mathrm{m}^{3}$.

If pores are stabilized on entangled dislocations and dislocation clusters are fastened on precipitates, it can be concluded that there is a relation between the final pore density and the initial precipitates density, formed early in the life. In addition the precipitates density is probably correlated to the local fuel intra-granular stress, or to the pre-existing precipitates in case of fuel manufactured with additives. TEM pictures should be performed on the N118 fuel where few grains subdivision was observed. It would be indeed interesting to check the dislocations feature prior to the HBS formation in such a fuel.

The inter-bubbles strain fields could induce dislocations sources, as suggested in figure 18 . The pictures also suggest the piling up of these dislocations, able to progressively isolate matrix portions by construction of dislocations walls (figure 16). The final sub-grain is the achievement of

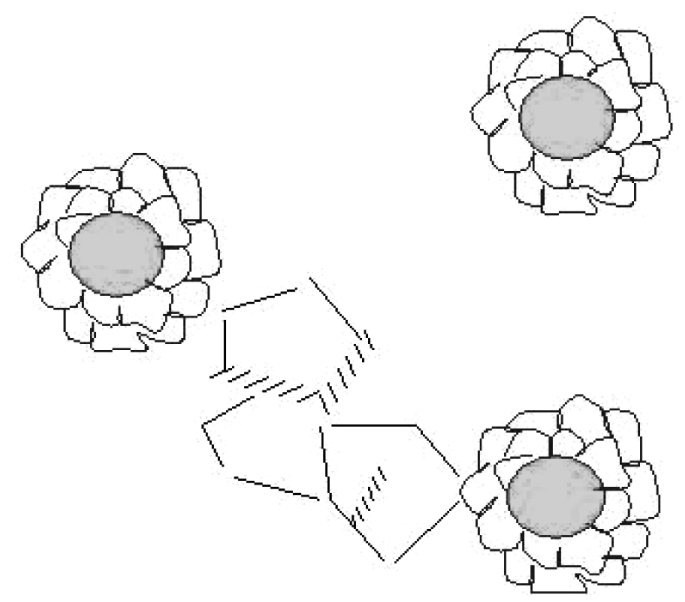

Fig. 19. Grains Subdivision Process in the Inter-pores Areas

these processes. The isolated matrix tends to slightly rotate and relax part of the internal energy. XRD measurement confirms a slight miss-orientation of the new sub-grains. Figure 17 shows the final HBS structure as seen on TEM observations. Figure 19 represents very schematically the dislocations piling and sub grain apparition, between the micrometric pores surrounded by tiny round grains.

Unfortunately TEM pictures cannot be properly localized within the inter-pores material because they are performed on fuel chips obtained by sample's crushing. A chip 100 to $200 \mathrm{~nm}$ thick of irradiated fuel would be necessary to perform this measurement, which is technically impossible up to now. The remaining question is now: where from the grain subdivision propagates? They are two possibilities: from the pores surface sub-grains or from the inter-pores mid region. Some authors have suggested a kind of punching phenomenon related to pores pressurization. Another possibility is that inter-pores zones are highly stressed and that pores tend to decrease the stiffness in their surrounding. The observation of the influence of the micro-pores density reported here above is in favour of the second assumption.

\section{CONCLUSIONS}

High burn-up transformation process in low temperature nuclear fuel oxides material was observed very early in the sixties in LWR fuels (Shipping port) but not studied in depth. Increasing progressively the fuel discharge burnup in PWR power plants, this material transformation was again observed in 1985 and identified as an important process to be accounted for in the fuel simulations, due to its expected consequence on fuel heat transfer and therefore on the fission gas release. Fission gas release is one of the major concerns in PWR fuels, mainly during transient 
accidental events. The behaviour of such a material in case of rod failure is also an important aspect to be analysed.

Therefore several national and international programmes were launched to understand the mechanisms leading to the high burn-up structure formation and to evaluate the physical properties of the final material. A large observations database has been gathered for more than twenty years, using the most sophisticated observation and measurement techniques available in hot cells on irradiated materials.

We have used in this paper most of this database, trying to extract the state of the art on the HBS transformation. Unfortunately, several of the base mechanisms are operating at scales not accessible with the usual investigations methods. Therefore we have extrapolated assumptions consistent and compatible with the overall observations, in order to propose a likely mechanism of the HBS formation. In order to go further in modelling, basic parameters must be evaluated by first principle calculation or very targeted experiments. Multi-scale approaches become necessary as proposed in the NXO Japanese project, to define what is possible and what is not. For example, is the oxygen redistribution able to form planar oxygen clusters? The behaviour of a highly irradiated ionic material remains still complex as far as the fission products interact not only with the irradiation defects, but also between them.

Nevertheless, this paper shows that, even if there is a large number of pending questions, we have already enough materials to develop a new generation model for engineering simulation codes. Our next work will propose simplified parametric studies, based on Representative Elementary Volume calculations suggested by the described mechanisms. The aim of this paper was to trigger discussions and also provide tracks for further investigations.

\section{ACKNOWLEDGMENTS}

It is difficult to thank all the researchers who brought useful information in this paper as it is based on results collected during the past 25 years at CEA, TUI and NFD labs and in the past UKAEA lab. The initial meeting point of all these researchers was probably around the BK365 fuel samples (83 GWd/MtU pellet average burnup) provided by Framatome for the HBEP project. A sample from this fuel was sent inadvertently to Dr K.Une's laboratory who used it with talent. This was a good overall operation and the beginning of a large cooperation and fruitful discussions. We would like to thank the HBEP team, the HBRP team, the EPRI FPAG group and obviously all the authors cited in the selected references. Finally we would like to thank Pierre Chantoin who participates indirectly to this publication.

\section{NOMENCLATURE}

$\begin{array}{ll}\text { ANS } & \text { American Nuclear Society } \\ \text { BU } & \text { Burn-up } \\ \text { CEA } & \text { Commissariat à l'Energie Atomique }\end{array}$

$\begin{array}{ll}\text { EDF } & \text { Electricité De France } \\ \text { ENS } & \text { European Nuclear Society } \\ \text { FGR } & \text { Fission Gas Release } \\ \text { FP } & \text { Fission Products } \\ \text { HBEP } & \text { High Burn-up Effect Program } \\ \text { HBS } & \text { High Burn-up structure } \\ \text { HBRP } & \text { High Burn-up Rim Project } \\ \text { IAEA } & \text { International Atomic Energy Agency } \\ \text { JNES } & \text { Japanese Nuclear Energy Society } \\ \text { JNM } & \text { Journal of Nuclear Materials } \\ \text { MOX } & \text { Mixed Oxides Fuel } \\ \text { NFIR } & \text { Nuclear Fuel Industry Research group } \\ \text { NXO } & \text { New cross Over Project } \\ \text { PWR } & \text { Pressurized Water Reactor } \\ \text { SEM } & \text { Scattering Electron Microscopy } \\ \text { SRIP } & \text { Slice Re-Irradiation Project } \\ \text { TEM } & \text { Transmission Electron Microscopy } \\ \text { TUI } & \text { Trans Uranium Institute } \\ \text { XRD } & \text { X Ray Diffraction }\end{array}$

\section{REFERENCES}

[1] M.L.Bleiberg, R.M.Berman and B.Listman, proceedings Symposium on Radiation Damage in solids and Reactor Materials, IAEA, Vienna 1963, pp319

[2] D.Baron, "Abnormal Porosity Buildup in the Fuel Periphery at High Burn-up", $9^{\text {th }}$ HBEP Review, Wengen (Switzerland), june $9^{\text {th }}, 1986$.

[ 3 ] J.O.Barner, M.E.Cuningham, M.D.Freshley, D.D Lanning, "High Burn-up Effect Program - Final Report", HBEP-61, 1990, Battelle Pacific Northwest Laboratories.

[4] D.Baron, B.Bordin-Lhermitte, J-P Piron , "an Attempt to simulate the Porosity Build-up in the Rim at High Burn-up", IAEA Technical Commitee Meeting on Advances in Pellet Technology for improved Performance and High Burn-up Toranomon Pastral, TOKYO, JAPAN, October $26^{\text {th }}-$ November $1^{\text {st }}, 1996$.

[ 5 ] M.Kinoshita et al, "Final Report of High Burn-up Rim Project (HBRP), CRIEPI (2001).

[6] M.Kinoshita et al, "High Burn-up Rim Project II, Irradiation and examination to investigate rim-structured fuel" ANS Meeting, april 9-13 2000, Park City, USA (ANS CD-Rom).

[7] L.Desgranges, B.Pasquet, "Measurements of Xenon in Uranium dioxide $\left(\mathrm{UO}_{2}\right)$ with SIMS", Journal of Nucl. Mat. 215 (2004) pp 245-551

[ 8 ] J.Lamontagne, J.Noirot, L.Desgranges, T.Blay, B.Pasquet, I.Roure, "Detection of Gas Bubbles by SIMS in irradiated Materials", Microchemica Acta 145 (2004) pp91-94.

[9] J.Spino, D.Baron, M.Coquerelle, A.D.Stalios, "High Burnup Rim Structure: Evidence that Xenon Depletion, Pore Formation, and Grain Subdivision start at Different Local Burn-ups”, Journal of Nucl. Mat. 256 (1998) 189-196.

[10] Jeff Rest, G.L. Hofman, "An alternative explanation for evidence that Xenon depletion, pore formation and subdivision begin at different burn-ups", Journal of Nucl. Mat. 277(2000), pp 231-238.

[11] J.Spino, D.Papaioannou, "Lattice contraction in the rim zone as controlled by recrystallization : additional evidence", letter to the editor, Journal of Nucl. Mat. 372 (2008) pp 416-420. 
[12] N.Lozanno, L.Desgranges, "High Magnification SEM Observations for two types of Granularity in a High Burnup PWR Fuel Rim", Journal of Nucl. Mat. 257 (1998) p78.

[13] M. Kinoshita, T. Sonoda, S. Kitajima, A. Sasahara, E. Kolstad, Hj. Matzke, V.V. Rondinella, A.D. Stalios, C.T. Walker, I.L.F. Ray, M. Sheindlin, D. Halton, C. Ronchi, "High Burnup Rim Project (II) Irradiation and Examination to Investigate Rim-Structured Fuel", Proc. Int. Conf. on LWR Fuel Performance, ANS, Park City, Utah, April 9-14, 2000, p. 590-603.

[14] J.Soullard, "Contribution à l'étude des défauts de structure dans le bioxyde d'Uranium", PHD work presented on October $8^{\text {th }}$, 1976, faculté des Sciences de Poitiers, report CEA-R-4882 CEN Fontenay-aux-roses.

[15] J.Noirot, L.Desgranges, J.Lamontagne, "Detailed Characterisations of High Burn-up Structures", Journal of Nucl. Mat. 372 (2007) pp318-339.

[16] T. Sonoda, M. Kinoshita, I.L.F. Ray, T. Wiss, H. Thiele, D. Pellottiero, V.V. Rondinella, Hj. Matzke, "TEM observation on irradiation-induced microstructural evolution in high burn-up $\mathrm{UO}_{2}$ disk fuel", Nucl. Instr. Meth. Phys. Res. B191 (2002) 622-628.

[17] Kazuhiro Nogita and Katsumi Une, "Radiation-induced Microstructural Change in High Burnup $\mathrm{UO}_{2}$ Fuel Pellets", Nuclear Instruments and Methods in Physics Research B 91 (1994) 301-306.

[18] J.Jonnet, "A Contribution to the Understanding of the High Burn-up Structure Formation in Nuclear Fuel", Thèse soutenue à L'Institut National Polytechnique de Lorraine, Mécanique et Energétique, 9 Janvier 2007.

[19] M. Iwasawa, Y. Chen, Y. Kaneta Yasunori, T. Ohnuma, HY. Geng, M. Kinoshita, "First-principles calculation of point defects in uranium dioxide", Materials transactions ISSN 1345-9678, vol. 47, no11, pp. 2651-2657, 2006

[20] W.H. Hall, G.K.Williamson, Proc. Phys. Soc. A62, 631, 1959.

[21] G.K.Williamson, W.H. Hall, "XRAY line broadening from filed Aluminium and Wolfran", acta Mettall. 1, pp 22-31, 1953.

[22] Paul Van Uffelen, "Contribution to the Modelling of Fission Gas Release in Light Water Reactor Fuel", PhD report January 8th 2002, University of Liège, Faculty of Applied Sciences, Nuclear Engineering Department

[23] K.Une, M.Hirai, K.Nogita, et al, "Rim Structure Formation and High Burn-up Fuel Behaviour of large-grained $\mathrm{UO}_{2}$ Fuels", Journal of Nucl. Mat. 278 (2000) n ${ }^{\circ} 1$ pp54-63.

[24] D.Baron presentation, Proceedings on CD-ROM (2004) P11 ORA/PRO. RNK: V/458/04 Van Uffelen et al, International Workshop on the High Burn-Up Structures in Nuclear Fuels.

[25] M.Kinoshita, Takanori Kameyama et al, "HBRP_NT Final report n²”, July 2005 (restricted access).

[26] Laurent Bourgeois, PhD “Contribution à l'Etude du rôle des dopants dans la densification et la croissance cristalline du dioxyde d'Uranium", INPG PhD presentation June $17^{\text {th }}$, 1992, CEA Report CEA-R-5621, 1993.

[27] J.Noirot, L.Desgranges, P.Marimbeau, "Fission Gas Behavior in Water reactor Fuels", Seminar Proceedings Cadarache, France September 26-29 2000, NEA/OECD, NEA \#03053, 2002 p 223 (ISBN 92-64-16715-X).

[28] J.Spino, P.Peerani, "Oxygen Stochiometry Shift of Irradiated LWR-fuels : a Review. Implications for gas release", Journal of Nucl. Mat. 375 (2008) pp 8-25.
[29] K.Une, S.Kashibe, K.Hayashi, "Fission Gas Release Behavior in High Burn-up $\mathrm{UO}_{2}$ Fuels with develloped Rim Structure", Actinides 2001, Hayama, Japan, Nov 4-9, 2001.

[30] D.Baron, R.Masson, J-M.Gatt, J.Spino, D.Laux, "Evolution of the Fuel Mechanical Properties with Burn-up, an Extensive European Experimental Program”, 2005 Water Reactor Fuel Performance JNS-ENS-ANS meeting, October 2-6, 2005, Kyoto, Japan.

[31] C.Ronchi, M. Sheindlin, D Staicu, M. Kinoshita, "Effect of burn-up on the thermal conductivity of Uranium dioxyde up to 100.000 MWd t-1.", J. Nucl Mater. 327 (2004), p. 58.

[32] V.V.Likhanskii, O.V. Khoruzhii, A.A Sorokin, "Physical Model of Rim-layer formation in $\mathrm{UO}_{2}$ Fuels", International Workshop on the High Burn-up Structure in Nuclear Fuels, TUI Karlsruhe, June $28^{\text {th }}-30^{\text {th }}, 2004$.

[33] M.Kinoshita, "Towards the mathematical Model of Rim Structure Formation", Journal of Nucl. Mat. 248 (1997) 185-190.

[34] J.Rest, "A model for the influence of microstructure, precipitate pinning and fission gas behavior on irradiationinduced recrystallisation of nuclear fuels" Journal of Nucl. Mat. 326(2004) pp 175-184.

[35] J.Rest, "A model for the effect of the progression of irradiated-induced recrystallisation from initiation to completion on swelling of UO2 and U-10Mo nuclear fuels", Journal of Nucl. Mat. 346 (2005) pp 226-232.

[36] G.Khvostov, Vladimir Novikov, Anatoli Medvedev, Serguey Bogatyr, "Approaches to Modeling of High Burn-up Structure and Analysis of its Effects on the Behaviour of Light Water Reactor Fuels in the START-3 Fuel Performance Code", paper 1104, 2005 Water Reactor Fuel Performance JNS-ENS-ANS meeting, October 2-6, 2005, Kyoto, Japan.

[37] Frédérico Garrido, "Crystallochemistry of Anion-excess Fluorite-type Uranium Oxides", $4^{\text {th }}$ NXO meeting, Accelerator and Computer Science to Study Fission Irradiation on Fuel Materials, Tokyo University, November 13-14, 2007.

[38] J-P.Berton, D.Baron, M.Coquerelle, "Chemical Stability and Physical Properties of Cesium Uranates", IAEA TCM, TOKYO, Japan, 29 October to 1 November 1996.

[39] J-P.Hiernaut, T.Wiss, J-Y.Colle, H.Thiele, C.T.Walker, W.Goll, R.J.M.Konings, "Fission product release and microstructure changes during laboratory annealing of a very high burn-up fuel specimen", Journal of Nucl. Mat. 377(2008) pp313-324.

[40] H.J.Geng, Y.Chen, Y.Kaneta, M.Kinoshita, Phys.Rev. B 77, 180101, 2008.

[41] H.J.Geng, Y.Chen, Y.Kaneta, M.Iwasawa, T.Ohnuma, M.Kinoshita, Phys.Rev. B 77, 104120, 2008.

[42] C.Walker, V.Rondinella, D.Papaioannou, S.Van Vinckel, W.Goll, R.Manzel, Journal of Nucl. Mat. 345 (2005) 192.

[43] H.J.Matzke, "Oxygen potential in the rim region of high burn-up UO2 fuel”, Journal of Nucl. Mat. 208 (1994) 18-24.

[44] H.J.Matzke, "Oxygen potential measurements in high burnup LWR UO2 fuel ", Journal of Nucl. Mat. 223 (1995) 1-5.

[45] I.L.F.Ray, H.J.Matzke, H.A.Thiele, M.Kinoshita, "An electron microscopy study of the RIM structure of a UO2 fuel with a high burn-up of $7.9 \%$ FIMA", Journal of Nucl. Mat. 245 (1997) 115-123.

[46] M.Kinoshita, T.Kameyama, S.Kitajima, H.J.Matzke, "Temperature and fission rate effects on the rim structure formation in a UO2 fuel with a burn-up of 7.9 \% FIMA", 
Journal of Nucl. Mat. 252 (1998) 71-78

[47] K.Lassmann, C.T.Walker, J.Van de Laar, F.Lindström, "Modelling the high burn-up $\mathrm{UO}_{2}$ Structure in LWR Fuel", Journal of Nucl. Mat. 226 (1995) pp 1-8.

[48] J.Nakamura (JAERI), "Strain of Crystal Lattice in Irradiated Fuel”, Fuel Safety Research Meeting, May 16-17 2007.

[49] P.Guedeney, M.Trotabas, M.Boschiero, C.Forat, "FRAGEMA
Fuel Behaviour Characterization at High Burn-up", ANS/ENS International Topical Meeting on LWR Fuel Performance, Avignon (France), April 21-24, 1991, P 627, Vol 2.

[50] I.L.F.Ray, H.J.Matzke, "Observation of a high burn-up rim-type structure in an advanced Plutonium-Uranium carbide", Letter to the Editors, Journal of Nucl. Mat. 250 (1997) 242-243. 